\title{
Assessment of anxiety and depression among substance use disorder patients: a case-control study
}

\author{
Ikram I. Mohamed', Hossam Eddin Khalifa Ahmad ${ }^{2 *}$, Shehab H. Hassaan² and Shymaa M. Hassan
}

\begin{abstract}
Background: Several evidences from epidemiologic and treatment studies indicate that anxiety disorders, depression, and substance use disorders commonly co-occur, and the interaction is multifaceted and variable. Epidemiological studies and investigations within clinical substance abuse populations have found an association between anxiety disorders, depression, and substance use disorders.

Results: The mean age was $28.1 \pm 6.5$ years. The majority belonged to the moderate socioeconomic status (52\%). Substance use disorder (SUD) patients expressed higher levels of anxiety and depression in comparison to the control group. Most of the study group (97\%) expressed different levels of anxiety. Eighty percent of them expressed high and moderate anxiety levels, and 20\% of caregivers were having mild anxiety levels. Ninety-three percent of the substance users expressed different levels of depression, either mild 12\%, moderate $9 \%$, or severe $72 \%$. The Drug Use Disorder Identification Test scores were positively correlated with anxiety $(r=0.256$ and $p=0.010)$ and depression $(r=0.330$ and $p=0.001)$. Moreover, it was found that anxiety and depression are positively correlated with each other's $(r=0.630$ and $p=0.001)$.

Conclusion: Substance use disorders are associated with high levels of anxiety and depression. More specifically, it is associated with severe depression and anxiety. There is an obvious association between the presence of anxiety and depression on the one hand and the severity of drug-related problems on the other hand. Depression and anxiety are commonly present together in patients with SUDs.
\end{abstract}

\section{Background}

The lifetime prevalence of any substance use in Egypt varies between $7.25 \%$ and $14.5 \%$ [1]. Substance use disorders, mood, and anxiety disorders are widespread among the general population [2-4] and are associated with substantial social, economic, and health loss [5-8]. Reports published in the Journal of the American Medical Association indicate that roughly 50\% of individuals with severe mental disorders are affected by substance abuse, $37 \%$ of alcohol abusers, and $53 \%$ of drug abusers who also have at least one serious mental illness, and of all people diagnosed as mentally ill, $29 \%$ abuse either alcohol or drugs [9].

\footnotetext{
* Correspondence: hossamkhalifa71@Yahoo.com

${ }^{2}$ Psychiatry Unit, Department of Neurology and Psychiatry, Assiut University, Assiut, Egypt

Full list of author information is available at the end of the article
}

Anxiety and depression are among the most common problems reported by persons seeking treatment for drug addiction. Primary psychiatric symptoms persist behind detoxification and remission of addictive behavior. From an addiction perspective, there may be significant risks associated with concurrent depression and anxiety symptoms, regardless of etiology [10].

Anxiety can be caused by drug addiction. Anxiety commonly occurs during the acute withdrawal phase of alcohol and can persist for up to 2 years as part of a post-acute withdrawal syndrome, in about a quarter of people recovering from alcoholism [11]. Depression and anxiety symptoms are among the most common problems reported by persons seeking treatment for drug addiction. Drug addiction, anxiety, and depression account for three-quarters of the disability attributed to mental disorders [12]. Depression and drug addiction are 
critical, not only because of their high prevalence but also because of their negative consequences. Individuals with co-morbid mental health and drug addiction often experience severe illness, disability, and poor treatment outcomes [13].

This study was done with the aim to assess levels of anxiety and depression among drug addict people.

\section{Methods}

\section{Study design}

This is a descriptive case-control study conducted at Assiut University Neuropsychiatry Hospital. This is an educational health facility, which provides both inpatient and outpatient mental health services to the entire population of Upper Egypt. The study was conducted from December 2015 until the end of May 2016.

\section{Participants}

The study included a selective sample of 100 patients with substance use disorder. Patients had to meet the following criteria to be included in the study: (i) to be 18 years or older, (ii) to be currently diagnosed with substance use disorder (SUD) according to Diagnostic and Statistical Manual of Mental Disorders (DSM-IV-TR), and (iii) to accept the participation in the study. Exclusion criteria included the following: (i) the patient had a known psychiatric diagnosis before being diagnosed with SUD, (ii) the patient was mentally retarded or has an organic brain disorder, and (iii) the patient has a chronic medical illness. The control group included 50 subjects without a history of the current or past history of SUD and free from chronic illnesses as well. They were recruited from the patients' relatives and the hospital staff.

Data were collected using face-to-face interviews conducted by a trained study team including a psychiatrist and psychologist. The researchers introduced themselves to participants before the interview and clearly expressed the purpose of the study, and consent was obtained from every participant.

\section{Measures \\ Socioeconomic assessment scale for the family}

We gathered information about socio-demographic information using this scale, which is prepared by Professor Abdel Tawab Abdullah, Faculty of Education, Assiut University, in 1998 and modified in 2010. It includes four main variables: [1] the educational level of the father and mother, [2] the occupation of the father and mother, [3] total family income, and [4] lifestyle of the family [14].

Drug Use Disorder Identification Test (DUDIT) Arabic version This scale has been developed in the original English language version by Berman in 2007 [15]. It was translated into Arabic and validated by Sfendla and colleagues in 2017 [16]. The purpose of the Drug Use Disorder Identification Test was to identify the use of patterns and various drug-related problems. It consists of 11 items, and the total score of this test was 44 points. A patient with 6 points or more probably has drugrelated problems (for example, risky or harmful drug habits that might be diagnosed as substance abuse/ harmful use or dependence), while a patient with 25 points or more is probably heavily dependent on drugs. The scale was reported to have good reliability using Cronbach's alpha $(0.780)$ and possesses a high validity using Pearson correlation, $(r=88 \%)$ for the total scale [15].

\section{Hamilton Anxiety Rating Scale (HAM-A)}

This scale has been developed by Max Hamilton in 1959 [17] and was translated into the Arabic language by Fatim in 1994 [18]. The purpose of this scale was to measure the severity of anxiety. The Hamilton Anxiety Rating Scale consists of 14 items; each item was scored based on a five-point Likert scale ranging from $(0)=$ Not Present to [4] $=$ Very Severe. The total score of this scale ranged from 0 to 56 and was divided into four levels: 17 or less indicated mild anxiety, from 18 to 24 indicated mild to moderate anxiety, 25 to 29 indicated a moderate to severe anxiety, and more than 30 indicated severe anxiety.

\section{Hamilton Depression Rating Scale (HAM-D)}

The Hamilton Rating Scale for Depression (HRSD), sometimes called the Hamilton Depression Rating Scale (HDRS) and abbreviated HAM-D, is based on a multiple item questionnaire and addresses depression indicators with special attention to the evaluation of recovery from depression [19]. Initially developed by Max Hamilton in1960 [20], it has gone through numerous revisions since then. The Arabic version has high reliability and validity $[21,22]$. The Hamilton Depression Rating Scale consists of 21 items to rate the severity of depression. Mild depression is ranging from 13 to 16 , moderate depression is ranging from 17 to 19 , and severe depression is ranging from 20 to above.

\section{Statistical analysis}

Data were analyzed using the Statistical Package for Social Studies (SPSS) software version 20. A descriptive analysis using means with standard deviation, frequency counts, and percentages was carried out. Pearson correlation coefficients $(r)$ were employed to address the relationship between caregiver burden and study variables [23]. 


\section{Results}

\section{Sociodemographic characteristics}

The study included 100 SUD patients and 50 healthy control; $73 \%$ live in rural areas and $27 \%$ in urban ones. Their mean age was 28.1 years $(\mathrm{SD}=6.5)$. Most of the patients were married (62\%) while $38 \%$ were singles. Most of the patients were graduates of either secondary school or its equivalent (67\%) or held a university degree (23\%). Fourteen percent of them have no job apart from the domestic affairs, and the rest are either employed (20\%), manual workers $(52 \%)$, or students $(10 \%)$ (Table 1). The majority of the participants in this study belonged to the moderate socioeconomic status group (52\%), while $22 \%$ belong to the low socioeconomic class and $26 \%$ were in the high socioeconomic class. A comparison between sociodemographic data shows no statistically significant difference between the SUD patients and healthy controls $(p=0.643)$ (Table 1$)$.

\section{Clinical characteristics of the study sample}

The results showed that the majority of drug addict people (83\%) are polydrug addict; they used several types of substances (e.g., tramadol-cannabis-opiates-alprazolam-heroin-nalbuphine), while $17 \%$ of them used only tramadol. The majority of the drug users prefer the oral route $(68 \%)$, while $32 \%$ of them used drugs through several routes (oral-inhalation-injection).

Table 1 Comparison between the SUD patients $(n=100)$ and the control group $(n=50)$ regarding socio-demographic data

\begin{tabular}{|c|c|c|c|c|c|c|}
\hline \multirow[t]{2}{*}{ Variables } & \multicolumn{2}{|c|}{ Drug addict people $(\boldsymbol{n}=100)$} & \multicolumn{2}{|c|}{ Drug non-addict people $(\boldsymbol{n}=50)$} & \multirow[t]{2}{*}{$x^{2}$} & \multirow{2}{*}{$\begin{array}{l}p \\
\text { value }\end{array}$} \\
\hline & No. & $\%$ & No. & $\%$ & & \\
\hline \multicolumn{7}{|l|}{ Age groups } \\
\hline $16-20$ years & 10 & 10.0 & 7 & 14.0 & \multirow[t]{4}{*}{6.478} & \multirow[t]{4}{*}{0.056} \\
\hline $21-30$ years & 56 & 56.0 & 22 & 44.0 & & \\
\hline $31-40$ years & 30 & 30.0 & 13 & 26.0 & & \\
\hline $41-50$ years & 4 & 4.0 & 8 & 16.0 & & \\
\hline Age, mean $\pm S D$ & \multicolumn{2}{|l|}{$28.1 \pm 6.5$} & \multicolumn{2}{|l|}{$30.9 \pm 8.7$} & 7.60 & 0.061 \\
\hline \multicolumn{7}{|l|}{ Marital status } \\
\hline Single & 38 & 38.0 & 13 & 26.0 & \multirow[t]{2}{*}{2.125} & \multirow[t]{2}{*}{0.144} \\
\hline Married & 62 & 62.0 & 37 & 74.0 & & \\
\hline \multicolumn{7}{|l|}{ Residence place } \\
\hline Rural & 73 & 73.0 & 39 & 78.0 & \multirow[t]{2}{*}{0.438} & \multirow[t]{2}{*}{0.507} \\
\hline Urban & 27 & 27.0 & 11 & 22.0 & & \\
\hline \multicolumn{7}{|l|}{ Level of education } \\
\hline Illiterate & 2 & 2.0 & 0 & 0.0 & \multirow[t]{6}{*}{17.909} & \multirow[t]{6}{*}{$0.002^{* *}$} \\
\hline Read and write & 2 & 2.0 & 0 & 0.0 & & \\
\hline Primary & 3 & 3.0 & 1 & 2.0 & & \\
\hline Preparatory & 3 & 3.0 & 1 & 2.0 & & \\
\hline Secondary & 67 & 67.0 & 19 & 38.0 & & \\
\hline University & 23 & 23.0 & 29 & 58.0 & & \\
\hline \multicolumn{7}{|l|}{ Occupation } \\
\hline Not work & 14 & 14.0 & 3 & 6.0 & \multirow[t]{5}{*}{1.325} & \multirow[t]{5}{*}{0.158} \\
\hline Employee & 20 & 20.0 & 17 & 34.0 & & \\
\hline Farmer & 4 & 4.0 & 1 & 2.0 & & \\
\hline Student & 10 & 10.0 & 8 & 16.0 & & \\
\hline Manual workers & 52 & 52.0 & 21 & 42.0 & & \\
\hline \multicolumn{7}{|c|}{ Socioeconomic status } \\
\hline Low & 22 & 22 & 11 & 22 & \multirow[t]{3}{*}{0.267} & \multirow[t]{3}{*}{0.643} \\
\hline Middle & 52 & 52 & 24 & 48 & & \\
\hline High & 26 & 26 & 15 & 30 & & \\
\hline
\end{tabular}

*Statistically significant correlation $(p<0.05)$

**Statistically significant correlation $(p<0.01)$ 
As regards the duration of substance use, $93 \%$ of the patients used a drug for more than 1 year. Sixty-seven percent of them reported that they started drug use because of many reasons such as the effect of bad friends, as an experiment, to give them strength and activity, to forget problems and feel relaxed, to improve sexual ability, to spend excessive money, and to relieve chronic pain. However, $12 \%$ of them reported that they used drugs because of the effect of bad friends only, $13 \%$ to give the patient strength and activity only, and $8 \%$ of them reported that they used drugs to forget problems and feel relaxed (Table 2).

\section{The drug-related problems}

The DUDIT results of the study group revealed that 95\% of drug addict people are probably heavily dependent on a drug, with the mean score is $31.45 \pm 2.47$. While $5 \%$ of them have probable drug-related problems, with the mean score is $22.20 \pm 2.49$ (Table 3 ).

\section{Levels of anxiety and depression}

According to HAM-D scale results, $72 \%$ of the study sample was found to have severe depression in comparison to $6 \%$ of the control group $(p<0.001)$. It is worth noting that only $7 \%$ of the SUD group did not have depressive symptoms in comparison to $64 \%$ of the control group ( $p \leq 0.001)$. The results were similar as regards to anxiety. The prevalence of severe anxiety was $67 \%$ in the study group in comparison to $14 \%$ in the control group $(p<0.001)$. Five percent only of the SUD group have mild anxiety symptoms in comparison to $52 \%$ of the control group ( $p \leq 0.001)$ (Table 4, Figs. 1 and 2).

\section{Correlation between socio-economic status, DUDIT, anxiety, and depression}

The socio-economic status is positively but nonsignificantly correlated with Drug Use Disorder Identification Test scores $(r=0.070$ and $p=0.487)$, anxiety $(r=$ 0.008 and $p=0.935)$, and depression $(r=0.048$ and $p=$ 0.638). Drug Use Disorder Identification Test score is positively and significantly correlated with anxiety $(r=$ 0.256 and $p=0.010)$ and depression $(r=0.330$ and $p=$ 0.001). Moreover, it was found that anxiety and depression are positively and significantly correlated with each other $(r=0.630$ and $p=0.001)$ (Table 5).

\section{Discussion}

The purpose of this study was to assess the levels of anxiety and depression among SUD patients. Another objective of this study was to determine the correlation between the level of anxiety and depression on the one hand and the socio-demographic variables and drug userelated problems on the other side.

The current study revealed that the majority of drug addict people were polydrug addict. This might be due to the fact that one drug is used as a base or primary drug, with additional drugs to leaven or compensate for the side effects of the primary drug and make the

Table 2 Clinical characteristics of the SUD patients $(n=100)$

\begin{tabular}{|c|c|c|}
\hline Clinical data & No. & $\%$ \\
\hline \multicolumn{3}{|l|}{ Diagnosis } \\
\hline Polydrug addict & 83 & 83.0 \\
\hline Single-drug addict & 17 & 17.0 \\
\hline \multicolumn{3}{|l|}{ Types of abused drug } \\
\hline Tramadol & 17 & 17.0 \\
\hline Mixed (tramadol-cannabis-opiates-alprazolam-heroin-nalbuphine) & 83 & 83.0 \\
\hline \multicolumn{3}{|l|}{ Methods of drug intake } \\
\hline Oral & 68 & 68.0 \\
\hline Mixed (oral-inhalation-injection) & 32 & 32.0 \\
\hline \multicolumn{3}{|l|}{ History of abused drug } \\
\hline Less than 6 months & 3 & 3.0 \\
\hline More than 6 months and less than 1 year & 4 & 4.0 \\
\hline More than 1 year & 93 & 93.0 \\
\hline \multicolumn{3}{|l|}{ Reasons for drug abuse } \\
\hline Bad friends & 13 & 12.0 \\
\hline To give the patient strength and activity & 12 & 12.0 \\
\hline To forget problems and feel flatten & 8 & 9.0 \\
\hline $\begin{array}{l}\text { Mixed (bad friends, trial, to give the patient strength and activity, to forget problems and feel flatten, weakness of sexual ability, } \\
\text { excessive money, chronic pain) }\end{array}$ & 67 & 67.0 \\
\hline
\end{tabular}


Table 3 Distribution of using patterns and various drug-related problems among SUD patients $(n=100)$ according to Drug Use Disorder Identification Test

\begin{tabular}{llllll}
\hline $\begin{array}{l}\text { Using patterns and various drug- } \\
\text { related problems }\end{array}$ & No. & $\%$ & & Range & Mean \pm SD \\
\cline { 5 - 6 } & & & Lowest score & Highest score & $22.20 \pm 2.49$ \\
\hline Probable drug-related problems & 5 & 5.0 & 18 & 38 & $31.45 \pm 2.47$ \\
Probably heavily dependent on a drug & 95 & $\mathbf{9 5 . 0}$ & 26 & 38 & $30.99 \pm 3.18$ \\
Total & 100 & 100.0 & 18 & 38 \\
\hline
\end{tabular}

experience more enjoyable with drug synergy effects or to supplement for the primary drug when supply is low [24]. These results are consistent with the findings of Panebiance et al. who revealed that the majority of drug addict people were polydrug addicts [25]. On the opposite side, Jabeen et al. found that more than half of drug addict people were single drug users [26].

The present study showed that about most of the drug users' sample had severe levels of depression in comparison to the non-users' and about more than two thirds of the drug users' group had a severe level of anxiety as well while the majority of drug non-addict people had a mild level of anxiety. Many theories have tried to explain the relationship between SUDs and mental illness such as causality theory [27], multiple risk factor/environmental triggers theory [28], and genetics/supersensitivity theory [29].

Some studies indicated that substance use has been linked to some kind of emotional distress prior to consumption [30,31]. Others indicated that substance use is often used as a method to relieve emotional problems [32], although its effects are not very durable or effective in the long term, as consumption tends to enhance depressive symptoms [33].

Many studies are in concordance with our results. For example, Hodgson et al. showed that more than two thirds of drug addict people had a severe level of anxiety [34], while the majority of drug non-addict people had a mild level of anxiety. Additionally, Pakhtunkhwa et al. demonstrated that most of the drug addict people tend to have severe levels of depression [35].

The results of this study showed a positive correlation between the presence of anxiety, depression, and substance-related problems elicited by DUDIT. Considering the mutual maintenance pattern of this comorbidity, it is not surprising that both anxiety, depression, and substance use disorders impact the course and treatment outcome for the counterpart condition. For example, studies have shown that anxiety and depressive disorders are related to increased severity of lifetime alcohol use disorders, increased lifetime service utilization among individuals with a substance use disorder, increased the severity of alcohol withdrawal, and higher relapse rates following substance abuse treatment [36-40].

The correlation between anxiety and depression in this study can be explained by the direct causation model which states that one disorder causes or lowers the threshold for the expression of the other disorder [41]. The shared etiology model also referred to as the correlated liabilities model [42] indicated that a common set of risk factors leads to the development of both depression and anxiety.

Table 4 Comparison between levels of anxiety and depression among SUD patients $(n=100)$ and control group $(n=50)$ according to HAM-A and HAM-D rating scales

\begin{tabular}{|c|c|c|c|c|c|}
\hline \multirow[t]{2}{*}{ Variables } & \multicolumn{2}{|c|}{ Drug addict people $(\boldsymbol{n}=100)$} & \multicolumn{2}{|c|}{ Drug non-addict people $(\boldsymbol{n}=50)$} & \multirow[t]{2}{*}{$p$ value } \\
\hline & No. & $\%$ & No. & $\%$ & \\
\hline \multicolumn{6}{|l|}{ Levels of anxiety } \\
\hline Mild & 5 & 5.0 & 26 & 52.0 & $<0.001^{* *}$ \\
\hline Mild to moderate & 15 & 15.0 & 13 & 26.0 & 0.104 \\
\hline Moderate to severe & 13 & 13.0 & 4 & 8.0 & 0.364 \\
\hline Severe & 67 & 67.0 & 7 & 14.0 & $<0.001^{* *}$ \\
\hline \multicolumn{6}{|l|}{ Levels of depression } \\
\hline Normal & 7 & 7.0 & 32 & 64.0 & $<0.001^{* *}$ \\
\hline Mild & 12 & 12.0 & 9 & 18.0 & 0.319 \\
\hline Moderate & 9 & 9.0 & 6 & 12.0 & 0.565 \\
\hline Severe & 72 & 72.0 & 3 & 6.0 & $<0.001^{* *}$ \\
\hline
\end{tabular}

*Statistically significant correlation $(p<0.05)$

**Statistically significant correlation $(p<0.01)$ 


\section{Levels of Anxiety}

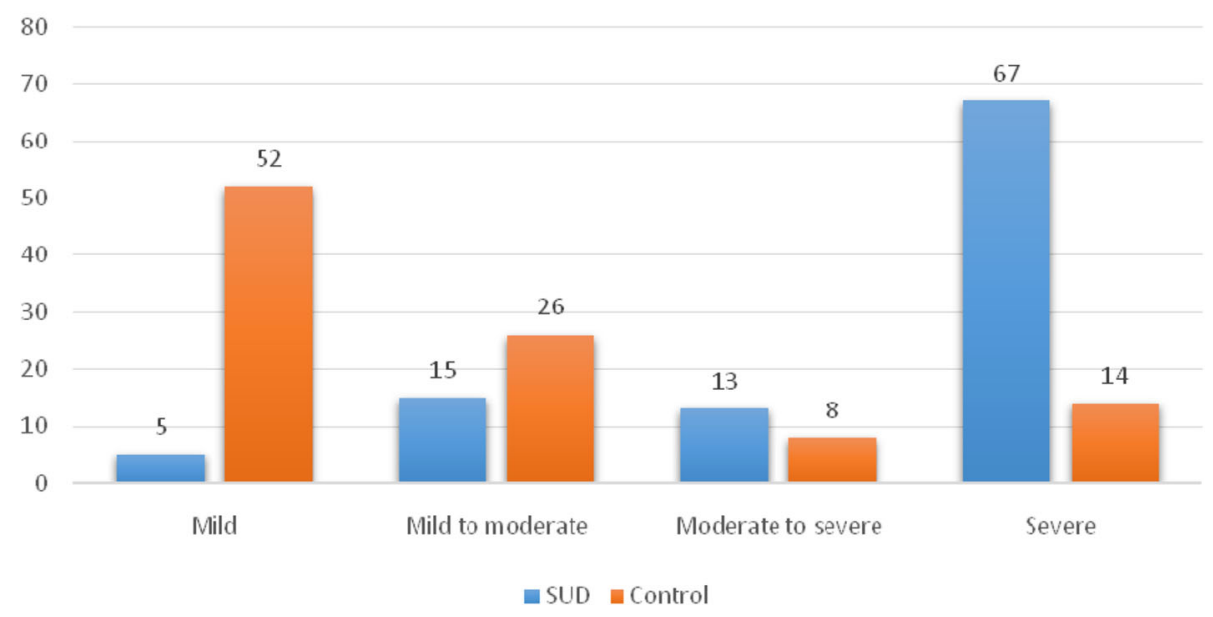

Fig. 1 Comparison between the SUD group $(n=100)$ and control group $(n=50)$ regarding anxiety levels according to the HAM-A rating scale

These findings are similar with the previous study reported by Grant et al. who found that anxiety is positively and significantly correlated with depression [43], whereas these findings are contradicted with Bellos et al. who found that anxiety is positively but non-significantly correlated with depression [44].

\section{Conclusion}

The prevalence of anxiety and depression among patients with substance use disorders is considerably high, and to be more specific, the level of severe depression and severe anxiety is the one we mean. There is an obvious association between the presence of anxiety and depression on the one hand and the severity of drug-related problems on the other hand. Depression and anxiety are commonly present together in the patients with SUDs. These findings throw the light on the problem of dual diagnosis and its impact on the prognosis and treatment process.

\section{Limitations}

The findings of this study should be cautiously interpreted because a small sample was used. The restriction of the sample prevents the findings from being generalized to the larger population. This study relies completely on self-reports.

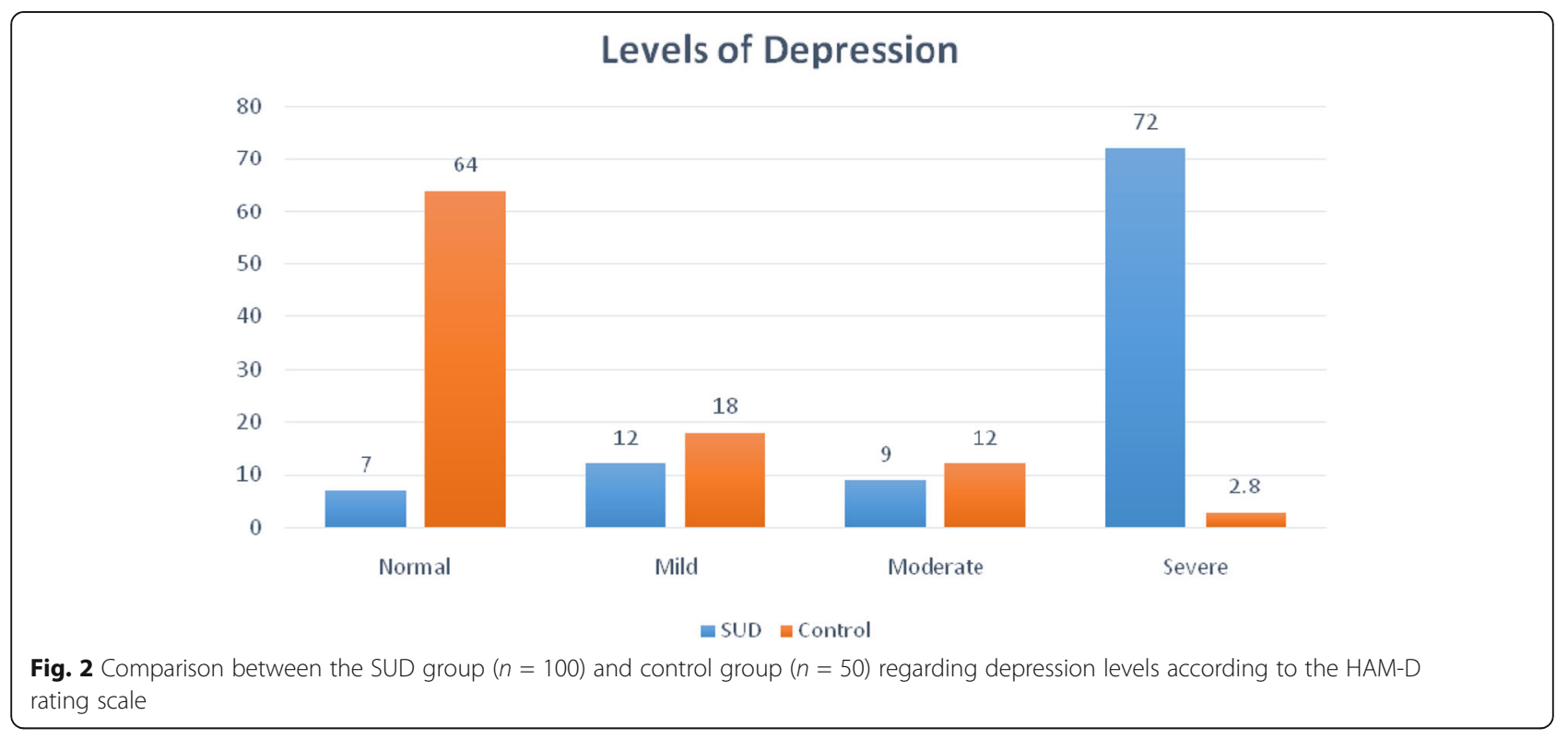


Table 5 Correlation between socio-economic status, Drug Use Disorder Identification Test, anxiety, and depression among SUD patients group $(n=100)$

\begin{tabular}{|c|c|c|c|c|c|}
\hline Variables & & Socio-economic status & Drug Use Disorder Identification Test & Anxiety & Depression \\
\hline \multirow[t]{2}{*}{ Socio-economic status } & $r$ & 1 & & & \\
\hline & $p$ value & & & & \\
\hline \multirow[t]{2}{*}{ Drug Use Disorder Identification Test } & $r$ & 0.070 & 1 & & \\
\hline & $p$ value & 0.487 & & & \\
\hline \multirow[t]{2}{*}{ Anxiety } & $r$ & 0.008 & 0.256 & 1 & \\
\hline & $p$ value & 0.935 & $0.010^{*}$ & & \\
\hline \multirow[t]{2}{*}{ Depression } & $r$ & 0.048 & 0.330 & 0.630 & 1 \\
\hline & $p$ value & 0.638 & $0.001^{* *}$ & $0.001^{* *}$ & \\
\hline
\end{tabular}

*Statistically significant correlation $(p<0.05)$

**Statistically significant correlation $(p<0.01)$

\section{Abbreviations}

DSM-IV-TR: Diagnostic and Statistical Manual of Mental Disorders; DUDIT: Drug Use Disorder Identification Test; HAM-A: Hamilton Anxiety Rating Scale; HAM-D: Hamilton Depression Rating Scale; SUD: Substance use disorder

\section{Acknowledgements}

Not applicable.

\section{Authors' contributions}

Ikram Mohamed contributed to the study design, interpretation of the data, and preparation and revision of the manuscript. HK contributed to the study design, collection and analysis, interpretation of the data, and preparation of the main manuscript. S. Hassaan and H. Khalifa contributed to the study design, interpretation of the data, and writing of the manuscript. Shymaa M. Hassan contributed to the analysis and interpretation of the data and revision of the manuscript. All authors approved the final manuscript.

\section{Funding}

The authors of this manuscript declare that no funding bodies were involved in sponsoring or funding this research, no grants were taken, and the research was conducted solely on the expense of the authors.

\section{Availability of data and materials}

The datasets that were generated during and/or analyzed during the current study are available from the corresponding author on reasonable request.

\section{Ethics approval and consent to participate}

Before starting data collection, the College of Nursing Ethical Committee approved the research in meeting no. 18 held on the 18th of December 2015 according to article 114 of its implementing regulations. Prior to the interview, written informed consent was obtained from the literate participants and was signed in the presence of a witness for illiterate ones. Privacy and secrecy of all data were assured by ensuring the anonymity of the questionnaire, interviewing the participants separately in a closed room, and keeping data files in a safe place.

\section{Consent for publication}

Not applicable

\section{Competing interests}

All authors declare no actual or potential conflict of interest whether financial, personal, or otherwise related to this manuscript.

\section{Author details}

${ }^{1}$ Faculty of Nursing, Assiut University, Assiut, Egypt. ${ }^{2}$ Psychiatry Unit, Department of Neurology and Psychiatry, Assiut University, Assiut, Egypt.
Received: 24 March 2020 Accepted: 27 March 2020

Published online: 03 June 2020

\section{References}

1. Hamdi E, Gawad T, Khoweiled A, Sidrak AE, Amer D, Mamdouh R, Loza N (2013) Lifetime prevalence of alcohol and substance use in Egypt: a community survey. Substance Abuse 34(2):97-104. https://doi.org/10.1080/ 08897077.2012.677752

2. Grant BF (1995) Comorbidity between DSM-IV drug use disorders and major depression: results of a national survey of adults. J Subst Abuse 7(4):481-497

3. Kessler RC, Nelson CB, McGonagle KA, Edlund MJ, Frank RG, Leaf PJ (1996) The epidemiology of co-occurring addictive and mental disorders: implications for prevention and service utilization. Am J Orthopsychiatry 66(1):17-31

4. Regier DA, Farmer ME, Rae DS, Locke BZ, Keith SJ, Judd LL, Goodwin FK (1990) Comorbidity of mental disorders with alcohol and other drug abuse. Results from the Epidemiologic Catchment Area (ECA) Study. JAMA 264(19): 2511-2518

5. Goetzel RZ, Hawkins K, Ozminkowski RJ, Wang S (2003) The health and productivity cost burden of the "top 10" physical and mental health conditions affecting six large U.S. employers in 1999. J Occup Environ Med 45(1):5-14

6. Roy-Byrne PP, Stang P, Wittchen HU, Ustun B, Walters EE, Kessler RC (2000) Lifetime panic-depression comorbidity in the National Comorbidity Survey. Association with symptoms, impairment, course and help-seeking. $\mathrm{Br} J$ Psychiatry 176:229-235

7. Sanderson K, Andrews G (2002) Prevalence and severity of mental healthrelated disability and relationship to diagnosis. Psychiatr Serv 53(1):80-86. https://doi.org/10.1176/appi.ps.53.1.80

8. Stewart WF, Ricci JA, Chee E, Hahn SR, Morganstein D (2003) Cost of lost productive work time among US workers with depression. JAMA 289(23): 3135-3144. https://doi.org/10.1001/jama.289.23.3135

9. NAMI: National Alliance on Mental Illness | NAMl: The National Alliance on Mental Illness. nami.org. Archived from the originalon 15 December 2012 Retrieved 20 October 2015

10. Weisner R, Thomas R, Mertens J (2006) Short-term alcohol and drug treatment outcomes predict long-term outcome. Drug and Alcohol Dependence, journal of psychiatric disorder 71(6):280-295

11. Johnson A (2011) Addiction medicine, science and practice. New York: Springer 5(3):301-303

12. Begg S, Barker B, Stevenson C, Stanley L, Lopez A (2007) The burden of disease and injury, in PHE 82. Canberra:44-48

13. Najt P, Fusar-Poli P, Brambilla P (2011) Co-occurring mental and substance abuse disorders: a review on the potential predictors and clinical outcomes Psychiatry Res 186(2-3):159-164. https://doi.org/10.1016/j.psychres.2010.07. 042

14. Abd Al-Twab A (1998) (2010). Family socio-economic status scale, revised edition, MD. Thesis in educational basics, faculty of education. Assiut University 3:32-55

15. Berman $\mathrm{AH}$, Palmstierna $T$, Kallmen $H$, Bergman $H$ (2007) The self-report Drug Use Disorders Identification Test: Extended (DUDIT-E): reliability, 
validity, and motivational index. J Subst Abuse Treat 32(4):357-369. https:// doi.org/10.1016/j.jsat.2006.10.001

16. Sfendla A, Zouini B, Lemrani D, Berman AH, Senhaji M, Kerekes N (2017) Psychometric properties of the Arabic version of the Drug Use Disorders Identification Test (DUDIT) in clinical, prison inmate, and student samples. International Journal of Behavioral Medicine 24(2):280-287. https://doi.org/10. 1007/s12529-016-9623-2

17. Hamilton M (1959) The assessment of anxiety states by rating. Br J Med Psychol 32(1):50-55

18. Fatim L (1994) Hamilton Anxiety Rating Scale. Alanglo library, Egypt

19. Hedlund JL, Viewig BW (1979) The Hamilton rating scale for depression: a comprehensive review. Journal of Operational Psychiatry 10:149-165

20. Hamilton M (1960) A rating scale for depression. Journal of Neurology, Neurosurgery and Psychiatry. 23(1):56-62

21. Bachner YG (2016) Psychometric properties of responses to an Arabic version of the Hamilton Depression Rating Scale (HAM-D6). Journal of the American Psychiatric Nurses Association 22(1):27-30. https://doi.org/10.1177/ 1078390316629959

22. Obeid S, Abi Elias Hallit C, Haddad C, Hany Z, Hallit S (2018) Validation of the Hamilton Depression Rating Scale (HDRS) and sociodemographic factors associated with Lebanese depressed patients. Encephale. https://doi.org/10 1016/j.encep.2017.10.010

23. IBM Corp. Released (2011) IBM SPSS Statistics for Windows, Version 20.0. IBM Corp, Armonk, NY

24. Eurosurveillance editorial, t. (2012) EMCDDA publishes 2012 report on the state of the drugs problem in Europe. Euro Surveill 17(46)

25. Panebianco D, Gallupe O, Carrington PJ, Colozzi I (2016) Personal support networks, social capital, and risk of relapse among individuals treated for substance use issues. Int J Drug Policy 27:146-153. https://doi.org/10.1016/j. drugpo.2015.09.009

26. Jabeen S, Raja S, Saeed S, Zafar M, Ghani A, Mahmood A, Raja G (2017) Factors influencing vulnerability towards heroin addiction in a Pakistani cohort, Pakistan. J. Zool 49(1):95-99

27. Dual Diagnosis Fact Sheet. (2013). National Alliance on Mental Illness. Retrieved from: http://www.nami.org/factsheets/dualdiagnosis_factsheet.pdf

28. Mental and Substance Use Disorders. (2014). Substance abuse and mental health services. Administration Center for Substance Abuse Treatment Retrieved from: http://www.samhsa.gov/disorders

29. Myers, C. (2014). Dual diagnosis, substance abuse and mental illness. Alternative Health and Mental Health

30. Huba GJ, Newcomb MD, Bentler PM (1986) Adverse drug experiences and drug use behaviors: a one-year longitudinal study of adolescents. J Pediatr Psychol 11(2):203-219

31. Kaplan HB (1985) Testing a general theory of drug abuse and other deviant adaptations. Journal of Drug Issues 15:477-492

32. Labouvie M (1996) Maturing out of substance use: selection an selfcorrection. Journal of Drug Issues 26:457-476

33. Bleichmar H (1994) Droga y depresión. Un camino a doble vía. Proyecto Hombre 10:11-14

34. Hodgson K, Almasy L, Knowles EE, Kent JW, Curran JE, Dyer TD et al (2016) Genome-wide significant loci for addiction and anxiety. Eur Psychiatry 36:4754. https://doi.org/10.1016/j.eurpsy.2016.03.004

35. Pakhtunkhwa P, PakistanNaz A, Khan W, Hussain M, Daraz U, Khan T, Khan Q (2012) The menace of opiate, the socio-psychological and physiological impacts of opiate on addicts in Khyber. African Journal of Pharmacy and Pharmacology 6(24):1753-1764

36. Driessen M, Meier S, Hill A, Wetterling T, Lange W, Junghanns K (2001) The course of anxiety, depression and drinking behaviours after completed detoxification in alcoholics with and without comorbid anxiety and depressive disorders. Alcohol Alcohol 36(3):249-255

37. Johnston AL, Thevos AK, Randall CL, Anton RF (1991) Increased severity of alcohol withdrawal in in-patient alcoholics with a co-existing anxiety diagnosis. Br J Addict 86(6):719-725

38. Sannibale C, Hall W (2001) (2001). Gender-related symptoms and correlates of alcohol dependence among men and women with a lifetime diagnosis of alcohol use disorders. Drug Alcohol Rev. 20(4):369-383

39. Perkonigg A, Settele A, Pfister $H$, Hofler M, Frohlich C, Zimmermann P, Wittchen HU (2006) Where have they been? Service use of regula substance users with and without abuse and dependence. Soc Psychiatry Psychiatr Epidemiol 41(6):470-479. https://doi.org/10.1007/s00127-006-0044-4
40. Thomas SE, Thevos AK, Randall CL (1999) Alcoholics with and without social phobia: a comparison of substance use and psychiatric variables. J Stud Alcohol 60(4):472-479

41. Avenevoli S, Stolar M, Li J, Dierker L, Ries Merikangas K (2001) Comorbidity of depression in children and adolescents: models and evidence from a prospective high-risk family study. Biol Psychiatry 49(12):1071-1081

42. Neale MC, Kendler KS (1995) Models of comorbidity for multifactorial disorders. Am J Hum Genet 57(4):935-953

43. Grant BF, Saha TD, Ruan WJ, Goldstein RB, Chou SP, Jung J et al (2016) Epidemiology of DSM-5 drug use disorder: results from the National Epidemiologic Survey on Alcohol and Related Conditions-III. JAMA Psychiatry 73(1):39-47. https://doi.org/10.1001/jamapsychiatry.2015.2132

44. Bellos S, Skapinakis P, Rai D, Zitko P, Araya R, Lewis G, Mavreas V (2016) Longitudinal association between different levels of alcohol consumption and a new onset of depression and generalized anxiety disorder: results from an international study in primary care. Psychiatry Res 243:30-34. https:// doi.org/10.1016/j.psychres.2016.05.049

\section{Publisher's Note}

Springer Nature remains neutral with regard to jurisdictional claims in published maps and institutional affiliations.

\section{Submit your manuscript to a SpringerOpen ${ }^{\circ}$ journal and benefit from:}

- Convenient online submission

- Rigorous peer review

- Open access: articles freely available online

- High visibility within the field

- Retaining the copyright to your article

Submit your next manuscript at $\boldsymbol{\nabla}$ springeropen.com 